\title{
Padrões Privados e a Atuação ou Omissão do Estado: Protecionismo Público-Privado?*
}

Manuela Amaral**

\begin{abstract}
A conscientização social quanto à importância da segurança e da qualidade dos produtos, além da crescente concentração industrial, contribuiu para a proliferação de normas e padrões privados. Nesse contexto, entes privados, como empresas, coalizões de empresas e organizações não governamentais, passaram a estabelecer requisitos técnicos para produtos e métodos e processos de produção - os quais consistem, muitas vezes, em barreiras não tarifárias ao comércio internacional. Apesar de não consistirem em exigências formalmente obrigatórias, constata-se, na prática, a obrigatoriedade da norma privada em razão das próprias condições de mercado. Entidades não estatais passaram, dessa forma, a complementar e, algumas vezes, substituir a atuação regulatória do Estado. Essa tendência ficou conhecida na literatura como "privatização da governança".
\end{abstract}

* Artigo recebido em 3 de julho de 2014 e aprovado para publicação em 20 de maio de 2015.

** Analista de Comércio Exterior no Ministério do Desenvolvimento, Indústria e Comércio Exterior (MDIC), Brasília, DF, Brasil. E-mail: manuela.amaral@gmail.com. 
A proliferação de medidas regulatórias voluntárias e privadas tem importante implicação para a Organização Mundial do Comércio (OMC) e, especificamente, para os Acordos de Medidas Sanitárias e Fitossanitárias (Acordo SPS) e de Barreiras Técnicas ao Comércio (Acordo TBT). Os Acordos da OMC estabelecem regras para medidas instituídas por governos ou entes relacionados a governos. Padrões e normas privados, estabelecidos por entes não governamentais, incluindo organizações da sociedade civil, empresas privadas e suas coalizões, não podem, em princípio, ser questionados diretamente na OMC.

Na medida em que padrões privados, que podem ser mais restritivos ao comércio do que medidas governamentais, têm sido uma forma cada vez mais comum de governança, teme-se que as regras multilaterais da OMC possam estar se tornando irrelevantes. Nesse contexto, em que medida as regras da OMC seriam aplicáveis a padrões privados e outras fontes não tradicionais de governança? Ou em que medida poderiam essas medidas ser atribuídas ao Estado para os efeitos das regras da OMC?

Estudo desenvolvido pela Organização das Nações Unidas para Agricultura e Alimentação (na sigla em inglês, FAO) salienta que os interesses privados promovidos por esses padrões privados estão frequentemente de acordo com interesses públicos (FAO, 2010). Em alguns casos, podem ser vistos como importante instrumento para implementação de políticas públicas. Nesse sentido, há um grande número de atividades governamentais que induzem essa governança liderada pelas forças de mercado. Cashore (2002) salienta que os mercados não operam de forma isolada das políticas governamentais, e o mesmo deve ser dito dessa governança liderada pelo mercado. Haveria, dessa forma, relação entre governos e regulação privada?

A fim de refletir a respeito da aplicação dos Acordos da OMC a instrumentos voluntários de regulação privada na área ambiental, pro- 
Padrões Privados e a Atuação ou Omissão do Estado: Protecionismo Público-Privado?

ceder-se-á ao estudo de três casos. A seleção dos casos baseou-se, sobremaneira, nos diferentes níveis de envolvimento governamental identificados. Nesse contexto, serão analisados o EU Timber Regulation, a Grenelle 2 e a Timberland Climate Strategy (2009). Em razão dos casos selecionados, o foco dessa análise se restringirá ao Acordo TBT e ao GATT 1994. Importante observar que não se pretende proceder a extensa análise jurídica a respeito da consistência das medidas selecionadas com a totalidade das regras da OMC. Pretende-se, apenas, verificar qual a margem existente, sobretudo no Acordo TBT, para o tratamento de eventual protecionismo privado.

\section{As Regras da OMC e a Regulação Privada}

Inicialmente, é preciso salientar que medidas governamentais visam influir no comportamento individual e, portanto, privado. Uma medida governamental pode, por exemplo, impor requisitos diretos sobre as entidades privadas para que ajam ou deixem de agir de determinada maneira. O governo também pode apresentar diferentes opções de comportamento e deixar aos entes privados a escolha daquelas que melhor atende a seus objetivos. Por fim, uma medida governamental pode regular o comportamento privado por meio de incentivos ou desincentivos mais fracos ou mais fortes para ações de entidades privadas sem, contudo, estabelecer ou impor uma obrigação direta. Tais incentivos podem consistir, por exemplo, na criação de condições favoráveis para a comercialização de produtos, na redução de impostos, na presunção de cumprimento de outras regras ou requisitos, entre outros.

No âmbito do Direito da OMC e da prática jurídica dos Painéis e do Órgão de Apelação, reconhece-se que os membros da OMC devem se responsabilizar por suas medidas, independentemente de exigirem entidades privadas a agir ou não de determinada maneira. Assim, os membros da OMC são, em geral, responsáveis, nos termos 
do GATT de 1994, por suas medidas governamentais quando essas forem capazes de distorcer as condições de concorrência e forçar entes privados a agirem de forma incompatível com as disposições dos acordos da OMC.

O GATT 1994, assim como outros acordos da OMC, não contém regras gerais para a atribuição de medidas privadas ao Estado. No entanto, parece estar claro que, se determinadas medidas privadas não puderem ser atribuídas a um membro, haveria margem para abusos e tentativas de os governos se esquivarem dessas regras multilaterais. Os membros da OMC poderiam, assim, disfarçar suas medidas como sendo não governamentais. Portanto, entende-se que medidas não governamentais, em algumas situações, podem e devem ser atribuídas aos membros da OMC.

Diante do exposto, analisar-se-ão, primeiramente, as brechas existentes no GATT 1994 e, em seguida, as existentes no Acordo TBT que podem permitir a responsabilização do Estado pela conduta de entes privados em seu território.

\subsection{Atribuição de responsabilidade ao Estado no GATT 1994}

Questões relativas à atribuição da responsabilidade ao Estado decorrente de conduta privada no âmbito do GATT 1994 surgiram várias vezes perante painéis do GATT e do Órgão de Solução de Controvérsias (OSC) da OMC. No caso Japan - Semi-Conductors, o Painel do GATT analisou ações da indústria de semicondutores japonesa, nas quais havia envolvimento do governo japonês (GATT, 1988). Nessa disputa, as Comunidades Europeias desafiaram as restrições voluntárias às exportações impostas pela indústria japonesa contra as exportações de semicondutores para os EUA. O Japão argumentou que a medida era proveniente do setor privado e, portanto, não passível de questionamento no âmbito do GATT. O Painel discordou e con- 
Padrões Privados e a Atuação ou Omissão do Estado: Protecionismo Público-Privado?

cluiu que uma estrutura administrativa havia sido criada pelo governo japonês, a qual exercia pressão suficiente para que o setor privado não exportasse a preços baixos. O Painel considerou que o complexo de medidas exibia rationale de um sistema formal de controle de exportação, apesar da ausência de obrigações formalmente vinculantes relativas à exportação de semicondutores. O Painel concluiu que essa diferença de forma não retirava o caráter mandatório dos requisitos estabelecidos pelo governo japonês. Assim, as restrições voluntárias e privadas à exportação de semicondutores foram atribuídas ao Japão, e o Painel concluiu ter o Japão violado o artigo XI:1 do GATT.

Posteriormente, após a criação da OMC, o Painel, no caso Japan Film, referiu-se à decisão acima quando houve, novamente, a necessidade de tratar da questão da atribuição de ações privadas aos membros da OMC no âmbito do GATT 1994 (OMC, 1998). Nesse contexto, observou-se que o fato de uma medida ser adotada por entes privados não exclui a possibilidade de ela ser considerada governamental caso haja envolvimento governamental suficiente. Nesse caso, quando as diretrizes administrativas do governo criam incentivos ou desincentivos para atores privados atuarem de determinada forma, a conduta privada poderá ser considerada governamental.

No entanto, se uma conduta privada não conta com envolvimento governamental significativo, ela não poderá ser atribuída a um membro da OMC. Nesse sentido, o Órgão de Apelação, no caso Korea - Beef, decidiu que se o comportamento privado não é exigido direta ou diretamente por lei ou regulamento governamental, mas resulta do próprio empreendedorismo privado, não há que se falar em violação do GATT (OMC, 2001a). Da mesma forma, o Painel, no caso China Audiovisual, não concluiu pela violação do GATT artigo III:4 em relação ao duopólio de distribuição de produtos de cinema na China, pois os Estados Unidos (reclamantes) não conseguiram demonstrar que o duopólio de distribuição havia sido criado, seja de facto ou de direito, por regras e regulamentos da China (OMC, 2010). 
Constata-se, dessa forma, que o OSC da OMC entende que o governo deve se responsabilizar pela conduta de entes privados na medida em que há algum tipo de incentivo. No âmbito do GATT 1994, as condutas de entes privados têm sido atribuídas ao Estado sem muita polêmica. A extensão desse entendimento ao Acordo TBT contribuirá sobremaneira para a responsabilização do Estado quanto a medidas técnicas restritivas ao comércio.

\subsection{Atribuição da responsabilidade ao Estado por condutas privadas no âmbito do Acordo TBT}

O objeto do Acordo TBT diz respeito tanto a regulamentos técnicos e padrões quanto a mecanismos de avaliação da conformidade. Regulamentos técnicos, conforme estabelecido no Anexo 1 do Acordo TBT, consistem em documentos que estabelecem características para produtos ou seus métodos e processos de produção relacionados, incluídas as disposições administrativas aplicáveis, cuja observância é obrigatória. Podem estar relacionados a terminologia, símbolos, embalagem ou requisitos de rotulagem, quando aplicados ao produto ou ao método e processo de produção. Esses exemplos indicam que o termo "características de produtos" diz respeito não apenas a características intrínsecas, mas também a características relacionadas aos produtos, como os meios de identificação, a apresentação e a aparência do produto.

Padrão, ou norma, consiste, por sua vez, em um documento aprovado por um órgão reconhecido ("recognized body"), que provê, para uso comum e repetido, regras, diretrizes ou características para produtos ou métodos e processos de produção relacionados, cuja observância não é obrigatória. Também pode incluir ou tratar de forma exclusiva de terminologia, símbolos, embalagens, requisitos de rotulagem, quando aplicáveis a produtos ou métodos de produção. Importante observar que não há, no Acordo TBT, definição ou qualquer outra in- 
Padrões Privados e a Atuação ou Omissão do Estado: Protecionismo Público-Privado?

dicação a respeito do que deve ser considerado como "órgão reconhecido".

O que distingue um padrão de um regulamento técnico é, em princípio, o caráter obrigatório da medida - o qual pode ser tanto de jure ou de facto. Assim, o documento do regulamento técnico poderá exigir, de forma positiva, que produtos contenham certas "características" ou, de forma negativa, que produtos não tenham certas "características". As características de um produto incluem, conforme definido no caso EC - Asbestos, qualquer característica, qualidade, atributo que possa ser definido ou identificado de forma objetiva. A "observância obrigatória" está relacionada ao caráter compulsório do instrumento que estabelece a medida e ao fato de prescrever que o produto deve, ou não, ter certas características. Vale mencionar ainda que o fato de a medida ser legalmente vinculante e obrigatória no âmbito da legislação doméstica - ou seja, ser editada pelo governo e incluir sanções em caso de descumprimento - consiste em componente importante do caráter "mandatório" da medida.

Existe antigo debate a respeito da aplicação das regras do Acordo TBT a métodos e processos de produção não relacionados às características finais do produto (Non Product Related Production and Process Methods - NPR-PPMs). Essa questão tem sido controversa e bastante sensível para muitos países-membros da OMC, uma vez que a utilização de requisitos baseados em métodos e processos de produção, sobretudo quando não se relacionam às características finais do produto, pode significar, na prática, a proteção de objetivos sociais localizados fora do território do membro que impõe a medida. Haveria, nesse caso, a aplicação extraterritorial da medida, o que tende a ser visto pelos membros da OMC como ameaça à autonomia regulamentar e, portanto, à soberania. Além disso, os requisitos baseados em métodos e processos de produção têm potencial de ser restritivos ao comércio, pois os produtores no exterior são compelidos a adequar suas instalações de produção às exigências regulamentares 
de terceiro país, as quais também podem diferir daquelas de outros membros da OMC. ${ }^{1}$

Um aspecto relevante relativo à aplicação das regras do Acordo TBT à regulação privada consiste nos entes supostamente obrigados a cumprir com as regras do Acordo. O Acordo TBT aplica-se, sobretudo, a órgãos governamentais centrais. Nesse sentido, o artigo 2.2, referente à "Preparação, Adoção e Aplicação de Regulamentos Técnicos por Instituições do Governo Central", dispõe que "os membros assegurarão que os regulamentos técnicos não sejam elaborados, adotados ou aplicados com a finalidade ou o efeito de criar obstáculos técnicos ao comércio internacional." O Acordo prevê, contudo, de forma explícita, a extensão de sua aplicação a outros entes envolvidos na preparação, adoção e aplicação de regulamentos técnicos, padrões e mecanismos de avaliação da conformidade, tais como instituições públicas locais e instituições não governamentais (artigo 3).

Instituições não governamentais são definidas, no Anexo 1 do Acordo TBT, como "instituição que não seja do governo central, nem instituição pública local, inclusive uma instituição não governamental legalmente habilitada para fazer cumprir um regulamento técnico." A definição de instituição não governamental parece ter sido formulada de maneira ampla. O conceito é formulado de forma negativa, especificando quais instituições não devem ser consideradas não governamentais. O uso da palavra "inclusive" na definição parece indicar, ainda, que o alcance do termo "instituição não governamental" no âmbito do Acordo TBT não se limita a apenas esses tipos de organismos não governamentais. Por fim, o fato de o Acordo ter especificado os conceitos de diversos órgãos governamentais e ter mencionado o termo "instituições não governamentais" induz a pensar que houve a intenção de incluir entidades não controladas pelo governo.

Importante observar que a extensão das obrigações relativas a regulamentos técnicos incidentes sobre órgãos públicos a instituições não 
Padrões Privados e a Atuação ou Omissão do Estado: Protecionismo Público-Privado?

governamentais e públicas locais ocorre por meio da responsabilização do governo em relação a esses entes. Nesse sentido, no que se refere a elaboração, adoção e aplicação de regulamentos técnicos por instituições públicas locais e instituições não governamentais em seu território, os membros, segundo o artigo 3.1 do Acordo TBT, "tomarão as medidas razoáveis a seu alcance para assegurar o cumprimento por tais instituições das disposições do artigo 2, com exceção da obrigação de notificar tal como contida nos parágrafos 9.2 e 10.1 do artigo 2".

No que diz respeito à obrigação do membro com relação a padrões elaborados e/ou estaelecidos por instituições públicas locais e instituições não governamentais existentes em seu território, o artigo 4.1 do Acordo TBT dispõe:

[Os membros] tomarão as medidas razoáveis a seu alcance para assegurar que as instituições de normalização públicas locais ou não governamentais existentes em seu território, bem como as instituições de normalização regionais das quais eles ou uma ou mais instituições existentes em seu território sejam membros, aceitem e cumpram este Código de Boa Conduta. Adicionalmente os membros não tomarão medidas que tenham o efeito direto ou indireto de obrigar ou encorajar tais instituições de normalização a agir de forma incompatível com o Código de Boa Conduta.

Nesse contexto, enquanto no caso de medidas emanadas de órgãos governamentais centrais a relação entre a regra da OMC e o Estado-membro é direta, no caso das medidas estabelecidas por órgãos não governamentais ou governamentais locais, a relação é indireta, baseada na adoção de medidas "razoáveis a seu alcance". Com base nesse raciocínio, é possível considerar que, caso empresas e coalizões de empresas possam ser consideradas instituições não governamentais, 
os membros podem ser demandados a adotar medidas "razoáveis a seu alcance" para que esses entes, em seu território, aceitem o Código de Boa Conduta.

A obrigação dos países-membros da $\mathrm{OMC}$ relativa à adoção de medidas "razoáveis a seu alcance" ainda não foi interpretada no âmbito da prática jurídica do OSC. Portanto, não há clareza a respeito de quais seriam essas obrigações e se haveria, no âmbito do Acordo, a necessidade de os membros adotarem medidas de "due diligence" com relação ao comportamento de certas entidades não governamentais, incluindo normas do setor privado. Digby Gascoine e O'Connor and Company (2007), ao refletir sobre o tema, citaram uma série de exemplos de medidas razoáveis que poderiam ser adotadas pelos membros da OMC quanto às organizações de normalização privadas, como: a divulgação de informações, o desenvolvimento e a difusão da política nacional, o diálogo com essas organizações e a celebração de memorandos de entendimento, concessão de incentivos financeiros para encorajar a conformidade com as boas práticas.

Percebem-se, dessa forma, algumas brechas nas regras da OMC para o tratamento de regulação privada. Nesse contexto, haveria duas formas de sujeitar medidas privadas às regras multilaterais de comércio da OMC. A primeira seria por meio da identificação de envolvimento governamental em esquemas de normalização e certificação privados. A esse respeito, vale recordar a decisão do relatório do painel, em Japan - Film, segundo a qual o fato de uma medida ser adotada por ente privado não exclui a possibilidade de ela ser atribuída ao governo caso haja suficiente envolvimento governamental (OMC, 1998). Nesse sentido, em caso de envolvimento governamental, o Estado poderia ser questionado no OSC em razão da não observância de regras da OMC.

A segunda diz respeito à exploração dessa relação indireta entre o Estado e essas instituições não governamentais. Nesse sentido, quais 
Padrões Privados e a Atuação ou Omissão do Estado: Protecionismo Público-Privado?

seriam as medidas razoáveis a serem adotadas pelo Estado para assegurar a observância das regras do Acordo TBT por parte de entes não governamentais? O recurso a essa relação indireta entre Estado e instituições não governamentais pode ser válido, sobretudo, nos casos em que não for identificada participação do governo na formulação ou na implementação do padrão privado.

A tentativa de responsabilizar o Estado por padrões privados visa, entre outros aspectos, evitar que órgãos governamentais se esquivem das regras multilaterais de comércio por meio da instituição de marcos regulatórios genéricos - no âmbito dos quais atores privados desempenham papel relevante na obtenção dos objetivos políticos e sociais do governo. A partir do momento em que se consegue vincular a atuação de entes privados normalizadores e certificadores ao governo, essas medidas privadas e semiprivadas devem observar os dispositivos das regras da OMC de uma forma geral e não somente o Acordo TBT. Mesmos nos casos em que não há vínculo entre o governo e a medida privada, ainda haveria que se falar em responsabilidade do Estado em razão de não ter adotado as "medidas razoáveis ao seu alcance", previstas no artigo 4.1.

Diante do exposto, tentar-se-á esclarecer as dúvidas existentes a respeito da aplicabilidade do Acordo TBT a diversos tipos de regulação privada por meio da análise dos casos selecionados e dos dispositivos relevantes do Acordo.

\section{EU Timber Regulation}

A União Europeia publicou, em 2003, o EU Forest Law Enforcement, Governance and Trade (FLEGT) Action Plan. O plano de ação baseia-se, principalmente, em dois mecanismos: Acordos de Parceria Voluntária (Voluntary Partnership Agreements - VPAs) e o EU Timber Regulation, os quais atuariam de forma conjunta no combate à extração ilegal de madeira e na melhoria da "governança" florestal. 
Diversos VPAs já foram celebrados, e o EU Timber Regulation (EU n. 995/2010) entrou em vigor em março de 2013.

VPAs consistem em acordos bilaterais com países exportadores de madeira e produtos derivados para facilitar o acesso ao mercado da União Europeia. Por meio desse acordo, o país exportador concorda em controlar e certificar a madeira legal. A assinatura do acordo implica na verificação por parte do país exportador da proveniência e da legalidade da madeira, para a qual será concedida a licença FLEGT. A análise de legalidade inclui verificação das operações florestais, controle do transporte e processamento. Trata-se, dessa forma, de um controle da cadeia de produção. Uma vez que o sistema de controle de legalidade instituído pelo país signatário do acordo for avaliado por instituição independente, a União Europeia só aceitará a importação de madeira licenciada desse país.

O EU Timber Regulation consiste, por sua vez, em legislação mandatória, introduzida como forma de reduzir a extração ilegal de madeira nas florestas mundiais. Visa regular a entrada e a comercialização de madeira e produtos derivados, incluindo móveis, papel e celulose, provenientes de países não signatários de VPAs. Para tanto, o regulamento proíbe a importação e a comercialização de madeira considerada "ilegal". A definição de "madeira legal" estará sujeita à legislação nacional dos países exportadores relativa aos aspectos ambientais e socioeconômicos, relacionados, sobretudo, ao manejo, à extração, ao processamento e à exportação de madeira.

Os importadores de madeira, sobretudo os que estiverem importando pela primeira vez, devem observar critérios relativos a due diligence e são integralmente responsáveis pela procedência e pela comercialização da mercadoria. Por due diligence, deve-se entender a necessidade de operadores europeus minimizarem o risco de importar ao mercado europeu madeira ilegal. Devem, portanto, avaliar a existência de madeira ilegal ao longo da cadeia de produção e serem capazes 
Padrões Privados e a Atuação ou Omissão do Estado: Protecionismo Público-Privado?

de responder a questionamentos a respeito: do local de extração da madeira, da governabilidade e da observância à legislação nacional, da capacidade de o exportador fornecer os documentos de forma confiável, do envolvimento de práticas de extração ilegal de madeira ao longo da cadeia produtiva, da complexidade da cadeia de produção. Documentos capazes de demonstrar conformidade à legislação nacional devem ser coletados como parte dos procedimentos relativos à análise de risco no âmbito da due diligence. A documentação pode estar relacionada à comprovação do direito de extrair madeira, estudos de impacto ambiental, entre outros.

OEU Timber Regulation estabelece, dessa forma, marco regulatório genérico ("proibição de importação de madeira ilegal"), que restringe importações e deixa que o setor privado se encarregue da adequação às exigências estabelecidas na medida regulatória. A delegação ao importador da prova da legalidade do produto transacionado obriga-o a adotar mecanismos para comprovar que os produtos adquiridos não foram extraídos e obtidos por meio ilegal. Nesse contexto, há incentivo para a adoção de certificações privadas ou públicas não estatais como forma de se isentar do risco e da responsabilidade legal imposta pelo regulamento. Tal prática tem sido crescente na União Europeia e parece sinalizar uma forma de o governo se esquivar das obrigações assumidas no âmbito da OMC. ${ }^{2}$

\subsection{Envolvimento governamental e a aplicabilidade do Acordo TBT}

O requisito relativo à comprovação da legalidade da madeira, exigido pelo EU Timber Regulation, poderia claramente ser considerado como regulamento técnico, caso estabelecesse características para produto ou método de produção. O regulamento, no entanto, proíbe a importação de madeira ilegal sem que o governo estabeleça critérios técnicos para esse termo. Em princípio, não está clara a aplicabilidade direta do Acordo TBT à exigência de comprovação de legalidade, 
conforme estabelecido pelo EU Timber Regulation. No entanto, é preciso ressaltar que o regulamento pode ter sido desenhado de forma a tangenciar essas regras. A responsabilização dos importadores pela origem de suas importações e a obrigação relativa à due diligence podem impor, na prática, o dever de atender a determinadas exigências relativas às características do produto e do processo produtivo sem, contudo, que o Estado seja diretamente responsável.

O Órgão de Apelação, em EC - Asbestos, estabeleceu teste em três etapas para verificar quando uma medida se encaixa no conceito de regulamento técnico conforme o Acordo TBT (OMC, 2001b). Nesse sentido, a medida deve: i) ser aplicável a um produto ou grupo de produto identificável; ii) estabelecer características para produtos; e iii) estabelecer observância obrigatória aos requisitos estabelecidos. De acordo com o Órgão de Apelação, a fim de identificar se todos esses requisitos foram preenchidos, a medida deve ser "examinada como um todo" e "à luz das características da medida e das circunstâncias do caso".

Nesse contexto, primeiramente, o regulamento técnico deve ser aplicável a um produto ou grupo de produtos identificáveis. Caso contrário, o controle da aplicação e da efetividade do regulamento será praticamente impossível. Contudo, esse requisito não exige que o produto tenha um "nome" específico ou que seja especificamente identificado no regulamento técnico. A esse respeito, o EU Timber Regulation diferencia claramente dois grupos de produtos, quais sejam: madeira e produtos derivados legais e ilegais.

Quanto ao segundo requisito, a regulamentação técnica deve estabelecer as características do produto, as quais possibilitam sua identificação. O sentido comum do termo "características do produto" é esclarecido pelo Órgão de Apelação por referência aos seus sinônimos, tais como: qualidades, atributos ou outra marca distintiva de um pro- 
Padrões Privados e a Atuação ou Omissão do Estado: Protecionismo Público-Privado?

duto. Importante observar que a especificação das características do produto não deve ser confundida com a medida que proíbe o produto.

Em EC - Asbestos, o Órgão de Apelação analisou se a proibição imposta a fibras de amianto por motivos de saúde pública podia ser qualificada como regulamento técnico na acepção do Acordo TBT (OMC, 2001b). O Órgão decidiu que a proibição desse material em seu estado natural, per se, não constitui regra técnica, pois não estabelece qualquer característica para fibras de amianto. No entanto, as medidas adotadas pelas Comunidades Europeias também objetivavam proibir produtos contendo fibras de amianto. O Órgão de Apelação concluiu que a exigência para que produtos não contivessem amianto correspondeu, justamente, à prescrição das características para o grupo identificável de produtos. Portanto, a medida foi qualificada como o regulamento técnico, conforme o Acordo TBT.

No caso EC - Seal Products, o Painel analisou o EU Seal Regime, similar ao EU Timber Regulation, que proíbe a importação e a comercialização de foca e seus derivados em território europeu (OMC, 2013). Esse regime prevê exceções baseadas na identificação do caçador e no propósito da caça, e, nesse sentido, produtos derivados de foca caçada por indígenas (inuits) poderão, por exemplo, ingressar no mercado europeu desde que acompanhados por certificados de órgão reconhecido. O Painel entendeu ser a medida um regulamento técnico, uma vez que define características para produtos de forma negativa, ao requerer que produtos não contenham foca. Além disso, a medida, por meio das exceções, estabelece "provisões administrativas aplicáveis" a produtos com "características objetivas".

O Órgão de Apelação, contudo, entendeu que, diferentemente da medida em EC - Asbestos, a proibição de importar produtos derivados de foca no EU Seal Regime não se deve ao fato de um produto conter foca, mas em razão da natureza do caçador e do propósito da caça (OMC, 2014). Assim, na medida em que os aspectos essenciais 
do regime não estabelecem características para produtos em si, as provisões administrativas não poderiam ser caracterizadas como aplicáveis às características do produto. Uma vez que o Órgão de Apelação concluiu que a medida não estabelece características para o produto, a decisão do Painel quanto à medida consistir regulamento técnico aplicado a produto foi revertida. O Órgão de Apelação não completou a análise quanto à possibilidade de a medida ser regulamento técnico aplicado a "métodos e processos produtivos relacionados". Considerando a similaridade entre o EU Seal Regime e o EU Timber Regulation, verifica-se a possibilidade de essas exigências serem consideradas regulamentos técnicos em razão de estabelecerem características para métodos e processos de produção.

Por fim, o terceiro e mais importante critério para caracterização de regulamento técnico diz respeito ao cumprimento obrigatório. Importante observar que a definição de regulamentação técnica, disposta no Anexo 1 do Acordo TBT, não especifica métodos particulares para que a medida se torne obrigatória. Esse entendimento foi confirmado pelo Painel no caso US - COOL (OMC, 2012b). Nesse sentido, o Painel ressaltou que, caso o termo "with which compliance is mandatory" contido na definição de regulamento técnico no Anexo 1 do Acordo TBT fosse interpretado de forma formalística, haveria margem para que os membros se esquivassem de grande parte de seus compromissos no âmbito do Acordo TBT ao qualificar suas medidas como não mandatórias ou de observância voluntárias.

No âmbito do EU Timber Regulation, verifica-se, na prática, a obrigatoriedade de comprovar a legalidade da madeira. Além disso, o fato de o importador ter de adotar medidas de due diligence e poder ser responsabilizado legalmente pela importação de madeira ilegal evidencia o caráter compulsório da adoção de medidas capazes de rastrear, certificar e comprovar a legalidade da extração da madeira. A esse respeito, o Painel em US - Tuna II constatou que o fato de a medida ser legalmente obrigatória no âmbito da legislação nor- 
Padrões Privados e a Atuação ou Omissão do Estado: Protecionismo Público-Privado?

te-americana corresponde a importante componente, mas não exclusivo, do caráter mandatório da medida (OMC, 2012a).

Uma análise mais cuidadosa do EU Timber Regulation pode concluir que a União Europeia, sem estabelecer documento tradicional com características para produtos e processos de produção, está estabelecendo exigências técnicas e estimulando certificação privada. A diferenciação entre madeira legal e madeira ilegal é feita, sobretudo, por meio das características do método de extração da madeira. A União Europeia parece, assim, ter optado por delinear as diretrizes gerais da política pública, sem, contudo, regular sua implementação, que ficou a cargo do importador. Essa estratégia pode contribuir para reduzir a responsabilidade do país-membro por eventuais medidas discriminatórias, arbitrárias e mais restritivas do que o necessário para atingir objetivos legítimos. Constata-se, assim, que a União Europeia tem induzido, por meio de políticas públicas com mecanismo de enforcement, determinada conduta por parte da sociedade civil, a qual pode, muitas vezes, ser inconsistente com as regras da OMC.

No entanto, o inegável envolvimento europeu na indução do comportamento de entes privados pode tornar a União Europeia responsável pela medida no âmbito da OMC. De acordo com relatório do painel, em Japan - Film, o fato de uma medida ser adotada por ente privado não exclui a possibilidade de ela ser considerada governamental caso haja suficiente envolvimento governamental (OMC, 1998). Nesse contexto, por mais que a União Europeia não tenha estabelecido regulamento técnico tradicional, com a identificação e a caracterização de madeira ilegal, a ser observado pelos importadores, existem características para o método e o processo de produção que devem ser observadas quando da importação de madeira ao mercado europeu. A fim de comprovar a conformidade a essas características, os importadores podem recorrer, de forma voluntária, à certificação privada. Verifica-se, assim, que a medida europeia, em razão do considerável envolvimento governamental e de seu caráter 
mandatório, pode ser considerada como regulamento técnico, atendendo aos requisitos estabelecidos pelo Órgão de Apelação em EC Asbestos (OMC, 2001b).

\section{França - Lei 2010-788: The National Commitment for the Environment (Grenelle 2 Law)}

O governo francês, na Grenelle de L'Environnement (2007), ${ }^{3}$ previu, entre diversas outras estratégias para promover o desenvolvimento sustentável, a rotulagem de carbono de produtos e serviços. De acordo com o Ministère de l'Écologie, du Dévelopment Durable et de l'Énergie (2013), uma estratégia política governamental baseada em informação e rotulagem apresenta vantagens em relação às políticas clássicas com potencial repressor. Segundo o governo francês, regulamentações e taxas podem influenciar negativamente o poder aquisitivo e a competitividade das empresas, sem mencionar a dificuldade em "calibrar" esse tipo de exigência. Políticas de rotulagem, ao contrário, visam solucionar problemas relativos à assimetria de informação prevalecente no mercado e propiciam maior facilidade de adaptação e menor custo. Além disso, o governo francês ressalta que a rotulagem permite evitar a fuga de poluição (pollution heavens), uma vez que produtos importados seriam submetidos às mesmas regras que os produtos nacionais. Por meio da rotulagem, seria possível, portanto, evitar o fenômeno da "délocalisation" dos impactos ambientais gerados por um consumo crescente de produtos importados. Para tanto, o governo francês reconhece a importância de mobilizar um conjunto de instrumentos políticos disponíveis a fim de alcançar resultados satisfatórios.

Essa estratégia para a proteção ambiental e o desenvolvimento sustentável, apoiada, sobretudo, em mudanças do comportamento do consumidor, ensejou duas legislações distintas, quais sejam: Grenel- 
Padrões Privados e a Atuação ou Omissão do Estado: Protecionismo Público-Privado?

le 1 , que consiste em quadro normativo geral, que estabelece princípios básicos para o programa ambiental do governo francês, e Grenelle 2, que regulamenta e especifica as disposições da Grenelle 1.

O artigo 228 da Grenelle 2 estabeleceu obrigação aos varejistas quanto à prestação de informações aos consumidores. $\mathrm{O}$ dispositivo previu o início da rotulagem de carbono em carácter experimental a partir de $1^{\circ}$ de julho de 2011 . Visou-se, com isso, informar o consumidor a respeito do conteúdo de carbono de produtos e embalagens e do impacto ambiental ao longo de seu ciclo de vida. De acordo com informe oficial, a intenção do governo é de que a rotulagem se torne obrigatória e incidente sobre produtos importados.

A esse respeito, o governo francês alega ser a proteção da competitividade das empresas ponto essencial para o sucesso da iniciativa de rotulagem e poderá ser garantida por meio da aplicação equivalente a produtos, independentemente de sua origem. $\mathrm{O}$ governo francês acrescenta que o objetivo da rotulagem não consiste em criar restrição disfarçada ao comércio internacional, pois produtos franceses e importados serão mensurados com base na mesma metodologia de cálculo. Visa-se, portanto, que produtos importados tenham a mesma performance ambiental que os franceses têm.

A fim de implementar as 268 conclusões da Grenelle, foram criados 23 comitês operacionais para cada um dos temas. O Comitê Operacional 23, responsável por questões relativas a consumidores, convidou o governo a apoiar iniciativas privadas de avaliação do impacto ambiental de diferentes categorias de produtos e a encorajar iniciativas voluntárias privadas relacionadas à prestação de informação ao longo da cadeia produtiva. ${ }^{4}$ Importante ressaltar que não há previsão de apoio financeiro governamental para as empresas optantes em aderir a esse programa voluntário. Ao contrário, participantes beneficiar-se-ão de suporte técnico e promoção da imagem. 
De forma paralela a essa iniciativa experimental, trabalhos técnicos foram desenvolvidos a fim de harmonizar a rotulagem em nível nacional. Nesse sentido, o governo francês trabalha: no desenvolvimento de metodologia padronizada para a mensuração do carbono e demais impactos ambientais; nos meios para divulgar as informações derivadas do impacto ambiental dos produtos; e em uma base de dados pública, administrada pela Agence de l'Environnement et de la Maîtrise de l'Énergie (ADEME), para assegurar a comparabilidade das avaliações do ciclo de vida entre as diversas categorias de produtos envolvidos no programa. Essas iniciativas visam, também, padronizar as formas de avaliação de impacto a fim de evitar, inclusive, disparidades entre iniciativas privadas voluntárias.

\subsection{Envolvimento governamental e a aplicabilidade do Acordo TBT}

O governo francês não considera que as exigências relativas à rotulagem de pegada de carbono sejam requisitos técnicos, conforme relatou representante governamental na reunião do Comitê sobre Barreiras Técnicas da OMC em setembro de 2011 (OMC, 2011). Portanto, não estariam sujeitas às regras estabelecidas pelo Acordo TBT. Tal argumentação é, contudo, questionável, pois, caso haja envolvimento governamental suficiente, é possível atribuir a rotulagem de carbono ao Estado francês para os efeitos da aplicação das regras da OMC.

Como visto, o governo francês estabeleceu, no âmbito da Grenelle 2, marco normativo geral para a rotulagem de carbono sem, contudo, determinar (ao menos inicialmente) norma ou regulamento técnico com a qual os produtos devem demonstrar conformidade. Nesse sentido, estabeleceu programa, inicialmente voluntário, no qual empresas participantes poderiam se beneficiar de assistência técnica e propaganda. $\mathrm{O}$ governo francês também se comprometeu a desenvolver metodologia harmonizada em âmbito nacional para mensurar pega- 
Padrões Privados e a Atuação ou Omissão do Estado: Protecionismo Público-Privado?

das de carbono. Enquanto isso, tem apoiado iniciativas privadas, como aquelas conduzidas por Casino e Leclerc. Nesse contexto, diversos selos e critérios para a mensuração da pegada de carbono estariam disponíveis no mercado francês - sem garantia de segurança e acuidade da informação prestada aos consumidores.

Nesse caso, assim como no EU Timber Regulation, é possível identificar envolvimento governamental. No caso da Grenelle, verifica-se a existência de estímulos e incentivos para as empresas atuarem de determinada maneira. Apesar de o programa não ser mandatório, constata-se a tentativa de reorientar o comportamento dos consumidores e estimular a demanda por produtos ambientalmente sustentáveis. Observa-se, mais uma vez, que o órgão governamental deixou, inicialmente a cargo das empresas, a regulação da sustentabilidade ambiental quanto à pegada de carbono. Nesse caso, o desenho da política Grenelle 2 pode ter sido feito de forma a evitar a responsabilidade do Estado pela adoção de medidas capazes de discriminar produtos similares.

O fato de o governo apoiar iniciativas privadas de certificação contribui para a legitimidade dessas medidas no mercado. Essa legitimação pode criar entraves desnecessários ao comércio. Nesse contexto, a Casino, por exemplo, poderá exigir a rastreabilidade das emissões de carbono por parte de seus fornecedores, e aqueles que não rastrearem ou não mensurarem as emissões de carbono não poderão fazer parte de sua política de compras. Além disso, vale ressaltar que a política de promoção e marketing do governo francês, como forma de induzir a participação das empresas no programa, poderá gerar vantagem competitiva para produtos rotulados e com baixa pegada de carbono.

Padrões privados, adotados e aplicados por entidades privadas, são voluntários por definição. No entanto, podem tornar-se de facto obrigatórios em algumas situações. No entanto, a distinção entre medida 
obrigatória e voluntária nem sempre é evidente. Os governos, por vezes, podem optar por não exigir diretamente o cumprimento obrigatório de uma medida. Em vez disso, podem fornecer incentivos para o cumprimento de uma medida formalmente voluntária. Em tais situações, determinar se a medida é obrigatória ou voluntária só poderá ser feito caso a caso - a depender do ambiente regulatório do país e do nível de envolvimento governamental. Além disso, vale mencionar que uma medida formalmente voluntária pode tornar-se obrigatória pelas próprias características do mercado.

Considerando a existência de programa governamental para a rotulagem de carbono e apoio e incentivos do governo francês a iniciativas privadas já existentes, como assistência técnica e marketing, evidencia-se envolvimento governamental em esquemas privados de pegada de carbono. Assumindo a existência desse vínculo, é possível atribuir responsabilidade ao governo pela conduta desses entes privados que regulam a rotulagem de carbono. É preciso verificar, contudo, se os incentivos governamentais são suficientes para tornar a medida $d e$ facto obrigatória.

Como visto, a definição de regulamentação técnica, contida no Anexo 1 do Acordo TBT, não especifica a forma pela qual a medida se tornará obrigatória. O caminho natural para impor regulamentação técnica obrigatória é por meio dos instrumentos legais adequados. No entanto, uma medida voluntária poderá tornar-se de facto obrigatória devido ao apoio governamental ou a incentivos para sua adoção e implementação. Por essas e outras razões, a medida deve ser analisada como um todo, conforme orientado pelo Órgão de Apelação.

No caso do programa de rotulagem de carbono estabelecido no âmbito da Grenelle, os incentivos governamentais para adequação à medida parecem ser insuficientes para tornar a medida obrigatória. Nesse sentido, não existem incentivos nem desincentivos financeiros capazes de alterar substancialmente o comportamento e os hábitos dos 
Padrões Privados e a Atuação ou Omissão do Estado: Protecionismo Público-Privado?

consumidores. Além disso, a indústria não incorrerá em prejuízo significativo caso não institua a rotulagem. Por fim, vale ressaltar que a medida tem caráter experimental e aplicação a universo reduzido de produtos. Por essas razões, entende-se que dificilmente essa medida, tal como se encontra hoje, caracterizar-se-ia como mandatória.

Independentemente da obrigatoriedade de facto da rotulagem, o aspecto discriminatório em termos comerciais é visível, sobretudo para produtos importados, cujas emissões decorrentes do transporte internacional são consideradas no cálculo da pegada de carbono. A não aproximação da medida da definição de regulamento técnico não afasta, contudo, a responsabilidade do governo francês pela conduta de entes privados. Nesse sentido, pode não haver envolvimento governamental suficiente para caracterizar regulamento técnico, mas pode haver envolvimento governamental suficiente para atribuir responsabilidade ao Estado pela conduta discriminatória do ente privado - como apontado pelo Painel no caso Japan - Film (OMC, 1998).

Nesse caso, independentemente da definição de instituição não governamental contida no Anexo 1 do Acordo TBT, as diferentes estratégias de rotulagem adotadas no âmbito do programa francês poderiam ser consideradas governamentais. $\mathrm{O}$ fato de haver envolvimento governamental nos esquemas privados e existir a iniciativa de criar uma norma nacional para a rotulagem dispensa a necessidade de analisar a ambiguidade do termo "instituições não governamentais" em mais detalhes. Haveria, nesse caso, envolvimento governamental suficiente para atribuir a atividade de padronização ao governo. Nesse sentido, vale recordar a primeira frase do artigo 4.1 do Acordo TBT, segundo a qual os membros assegurarão que suas instituições de normalização do governo central aceitem e cumpram o Código de Boas Práticas.

A obrigação do membro, nesse caso, consiste em assegurar que instituições de normalização do governo central observem o Código de 
Boas Práticas. O Código estabelece, em geral, que normas e padrões deverão observar a obrigação do tratamento nacional; evitar a criação de obstáculos desnecessários ao comércio internacional; basear-se em normas internacionais, quando existentes; contribuir para a harmonização de normas e regulamentos técnicos; e evitar a duplicação de esforços e a sobreposição de trabalho.

\section{Timberland's Climate Strategy}

A Timberland, empresa no ramo de calçados e vestuário, ao reconhecer a crescente conscientização ambiental e a capacidade de consumidores "votarem com seus dólares" em empresas que contribuem para a redução dos impactos ambientais, publicou, em 2009, uma estratégia para reduzir os impactos sobre a mudança climática. Nesse sentido, passou a investir em energia renovável e a promover melhorias em sua capacidade instalada para reduzir o consumo de energia. A fim de ser reconhecida como empresa responsável, a Timberland também se comprometeu a reduzir a pegada de carbono associada à sua cadeia produtiva.

A estratégia empresarial da Timberland pode gerar impactos comerciais ao longo da cadeia produtiva, uma vez que exige responsabilidade ambiental de seus fornecedores. A esse respeito, requer, ao longo da cadeia produtiva, que processos produtivos e matérias-primas observem classificação de impacto ambiental, como o Green Index. Esse índice mensura emissões de gases de efeito estufa produzidas desde a extração da matéria-prima ao produto final e permite, portanto, verificar a contribuição relativa das emissões decorrente da escolha dos fornecedores. As informações disponibilizadas pelo Green Index poderão orientar a escolha de fornecedores ambientalmente mais sustentáveis e contribuir para a meta Timberland de redução da pegada de carbono. 
Padrões Privados e a Atuação ou Omissão do Estado: Protecionismo Público-Privado?

Além de recorrer ao Green Index, a Timberland contribui para a padronização da mensuração de impacto ambiental e para a melhoria da performance ambiental de seus fornecedores, por meio de programas como Leather Working Group e Global Social Compliance Programme - ambas iniciativas estabelecem avaliação e mensuração de boas práticas para instalações fabris. A política de compras da Timberland é, dessa forma, orientada pelos resultados dessas avaliações ambientais.

\subsection{Envolvimento governamental e a aplicabilidade do Acordo TBT}

A Timberland Climate Strategy consiste em iniciativa efetivamente privada, na qual não se identifica envolvimento governamental. As exigências da Timberland podem, no entanto, se tornar de facto obrigatórias, caso sejam amplamente utilizadas e legitimadas pelos consumidores em determinado mercado. O artigo 4.1 do Acordo TBT confere um tipo de responsabilidade indireta em relação a instituições não governamentais. A segunda frase do referido artigo dispõe que os membros tomarão as medidas razoáveis a seu alcance para assegurar que as instituições não governamentais existentes em seu território aceitem e observem o Código de Boa Conduta.

Nesse contexto, clareza a respeito do conceito "instituições não governamentais" é indispensável a fim de verificar a aplicação do Acordo a esse tipo de regulação privada. Como visto anteriormente, a redação dos dispositivos do Acordo TBT não parece querer limitar a aplicabilidade do Acordo a apenas órgãos governamentais. A definição de instituição não governamental constante do Anexo 1 do Acordo é, como visto, ampla e não há clareza se entes privados constituem instituições não governamentais, como previsto no artigo 4.1 do Acordo. 
No caso de medidas efetivamente privadas, como a Timberland Climate Strategy, caso se considere conceito amplo de "instituições não governamentais", como explicitado acima, haveria a responsabilidade indireta de o Estado adotar medidas razoáveis para assegurar que a entidade normalizadora aceitasse e cumprisse com o Código de Boas Práticas do Acordo TBT. Além disso, haveria a responsabilidade de o Estado não estimular essas entidades a agirem em desconformidade com as regras do Acordo. Essa conclusão, contudo é bastante preliminar, uma vez que não há clareza a respeito do termo "entidade não governamental" - o que ocorrerá, apenas, quando houver interpretação por parte do Órgão de Apelação.

\section{Conclusão}

Medidas voluntárias privadas podem contar com diferentes níveis de envolvimento governamental, atenuando, dessa forma, seu caráter estritamente privado. Dependendo do nível do envolvimento governamental, é possível atribuir ao Estado a implementação da medida privada. Caso não fosse possível, os membros da OMC poderiam evitar as regras do Acordo TBT ao utilizar linguagem "soft" nos instrumentos legislativos e exigir a implementação da medida de forma rigorosa.

Constatou-se, com base na análise dos casos, que podem existir, em linhas gerais, três situações distintas relativas à atribuição de conduta privada ao Estado. A primeira consiste nos casos em que o Estado estabelece marco regulatório proibitivo genérico e encarrega, aos privados, a observância compulsória do regulamento e a implementação de suas diretrizes. Nesse caso, o governo deixou a cargo dos entes privados a adoção de medidas formalmente voluntárias de certificação, as quais, na prática, são obrigatórias. Como refletido no EU Timber Regulation, apesar de o governo não ter editado um regulamento técnico, observa-se a existência de medida técnica obrigató- 
Padrões Privados e a Atuação ou Omissão do Estado: Protecionismo Público-Privado?

ria. Nesse caso, não há grande dificuldade em atribuir a conduta privada ao Estado.

A segunda situação diz respeito aos casos em que medidas governamentais estimulam entes privados a atuarem de determinada maneira. O governo pode encorajar, por meio de incentivos fiscais, assistência técnica, propaganda e marketing, empresas, coalizões de empresas, entre outros entes governamentais, a atuar de maneira inconsistente com as regras da OMC. A conduta do ente privado poderia ser atribuída ao Estado em decorrência dos incentivos governamentais, como no caso da Grenelle 2. Nesse contexto, poderia haver responsabilidade do Estado pela conduta de entes privados que atuaram conforme orientação governamental. Seria possível concluir pela existência de uma responsabilidade direta do Estado quanto ao programa nacional de rotulagem de carbono e às medidas de estímulo ao setor privado. ${ }^{5}$

A terceira, por sua vez, corresponde, a exigências privadas que decorrem do próprio setor privado, como no caso da Timberland Climate Strategy. Não há, nessa situação, qualquer envolvimento ou estímulo do governo. A ausência de envolvimento governamental impossibilita a atribuição da conduta privada diretamente ao Estado. No entanto, o fato de o membro da OMC ter assumido compromissos internacionais, como o Acordo TBT, pode torná-lo responsável indiretamente pela conduta privada.

Nesse caso, o único vínculo passível de ser feito entre governo e ente privado seria por meio do recurso ao disposto no artigo 4.1 do Acordo TBT, segundo o qual o membro deve adotar as medidas razoáveis para que instituições não governamentais em seu território cumpram com o Código de Boas Práticas. Considerando conceito amplo de "entidades não governamentais", entende-se que a responsabilização do Estado decorre da não observância do compromisso internacional relativo à adoção de "medidas razoáveis" para assegurar a ob- 
servância do Código de Boas Práticas. Nesse caso, seria possível relacionar a conduta praticada por um ente privado considerada inconsistente com as regras da OMC à omissão do Estado em adotar as "medidas razoáveis".

Esse entendimento não é, contudo, unânime, pois a responsabilização indireta do Estado pela conduta de entes privados depende de esclarecimento a respeito do que consistem "entidades não governamentais" e "medidas razoáveis". O problema parece estar relacionado à precisão, ao escopo e à aplicação desses termos. Na medida em que não houve, até o momento, nenhum caso no âmbito da OMC que tenha envolvido padrões privados, as dúvidas permanecem quanto à aplicabilidade das regras da OMC a essas medidas puramente privadas.

\section{Notas}

1. Casos recentes contribuíram, contudo, para o esclarecimento dessa questão. Nesse sentido, as medidas questionadas tanto em US - Tuna II quanto em US COOL consistiam em requisitos de rotulagem NPR-PPMs, e, em nenhum desses casos, o demandado argumentou não serem as medidas em questão abrangidas pelas regras do Acordo TBT. Conclui-se, portanto, pela interpretação abrangente de métodos e processos de produção, os quais podem, então, estar ou não relacionados às características finais dos produtos. A confirmação dessa análise será feita, contudo, caso a caso.

2. A esse respeito, ver o Food Safety Act e o EU Seal Regime.

3. Informações disponíveis em: <http://www.developpement-durable.gouv.fr/-Le-Grenelle-de-l-environnement-de-.html>.

4. Entre as iniciativas privadas voluntárias apoiadas pelo governo francês, destaca-se, para efeito ilustrativo, o caso da Casino. O Índice de Carbono Casino (Indice Carbone) é a marca do grupo Casino, grande varejista francês, e foi desenvolvida em 2006 por uma consultoria ambiental (Bio Intelligence Service), cuja metodologia foi validada pela ADEME e implementada pela Casino 
Padrões Privados e a Atuação ou Omissão do Estado: Protecionismo Público-Privado?

desde 2008. O selo, um símbolo correspondente a uma folha verde, disposta na frente da embalagem do produto, indica a pegada de carbono calculada para o produto e expressa em gramas de $\mathrm{CO}_{2}$ por $100 \mathrm{~g}$ do produto. Na parte de trás do produto, o índice pode ser visualizado como uma tarja verde, que posiciona o impacto ambiental do produto em diferentes níveis. A graduação da escala é feita em parceria com a ADEME. A lista das 168 empresas participantes pode ser encontrada em: <http://www.developpement-durable.gouv.fr/Liste-alphabetique-des-entreprises.html>. Acesso em: 24 fev. 2014. Exemplos de iniciativas de rotulagem apoiadas pelo governo francês podem ser encontrados em: $<$ http://www.developpement-durable.gouv.fr/IMG/pdf/Exemples_illustrations_au_1er_septembre.pdf>. Acesso em: 24 fev. 2014.

5. Importante observar que, conforme entendimento no âmbito do GATT 1994, é natural que o governo seja responsabilizado por atos de entes privados em seu território que atuaram de forma consistente com suas orientações, sejam elas incentivos negativos, como proibições, ou positivos, como assistência técnica e marketing. Além disso, vale ressaltar que, no âmbito das regras do GATT 1994, um membro que se sinta prejudicado pela prática de empresas privadas em território de terceiro membro poderá adotar as medidas necessárias para anular os prejuízos decorrentes dessa prática. É o que ocorre no caso do dumping. O GATT não parece, dessa forma, ter negligenciado eventual conduta protecionista de entes privados.

\section{Referências Bibliográficas}

CASHORE, B. Legitimacy and Privatization of Environmental Governance: How Non-State Market Driven Governance Systems Gain Rule-Making Authority. Governance: An International Journal of Policy, Administration and Institutions, v. 15, n. 4, p. 503-529, out. 2002.

FAO - Food and Agriculture Organization of the United Nations. Private Food Safety Standards: Their Role in Food Safety Regulation and their Impact. Trabalho apresentado na 33를 Sessão da Codex Alimentarius Commisision. 2010.

GASCOINE, Digby; O'CONNOR AND COMPANY. Private Voluntary Standards within the WTO Multilateral Framework: Submission by the United 
Kingdom. Relatório preparado pela WTO, SPS Committee, G/SPS/GEN/802. Genebra, 9 out. 2007.

GATT - General Agreement on Tariffs and Trade. Relatório do Painel. Japan Semi-Conductors. L/6309 - 35S/116. Mai. 1988.

MINISTÈRE DE L'ÉCOLOGIE, DU DÉVELOPMENT DURABLE ET DE L'ÉNERGIE. Bilan au Parlement de l'Experimentation Nationale. Set. 2013. Disponível em: <http://www.developpement-durable.gouv.fr/IMG/pdf/Affichage_environnemental.pdf $>$. Acesso em: 10 jul. 2015.

OMC - Organização Mundial do Comércio. Relatório do Painel. Japan - Film. WT/DS44/R. Adotado em abril de 1998.

Relatório do Órgão de Apelação em Korea - Imports Measures on Fresh, Chilled and Frozen Beef. WT/DS161, 169/AB/R. Adotado em 10 de janeiro de 2001. 2001a.

Relatório do Painel. European Communities - Measures Affecting Asbestos and Asbestos Containing Products. WT/DS135/R e Add.1. Adotado em 5 de abril de 2001, modificado pelo Órgão de Apelação WT/DS135/AB/R. $2001 b$.

Relatório do Órgão de Apelação. China - Measures Affecting Trading Rights and Distribution Services for Certain Publications and Audiovisual Entertainment Products. WT/DS363/AB/R. Adotado em 19 de janeiro de 2010.

Comitê de Barreiras Técnicas. G/TBT/M/54. 20 de setembro de 2011.

Relatório do Painel. United States - Measures Concerning the Importation, Marketing and Sale of Tuna and Tuna Products. WT/DS381/R. Adotado em 13 de junho de 2012, modificado pelo Órgão de Apelação WT/DS381/AB/R. 2012a.

Relatório do Painel. United States - Certain Country of Origin Labelling (COOL) Requirements. WT/DS384/R/ WT/DS386/R. Adotado em 23 de julho de 2012, modificado pelo Órgão de Apelação WT/DS384/AB/R/WT/ DS386/AB/R. 2012b.

Relatório do Painel. European Communities - Measures Prohibiting the Importation and Marketing of Seal Products. WT/DS400/R, WT/DS401/R e Add.1. 25 de novembro de 2013. 
Padrões Privados e a Atuação ou Omissão do Estado: Protecionismo Público-Privado?

Relatório do Órgão de Apelação. European Communities - Measures Prohibiting the Importation and Marketing of Seal Products. WT/DS400/AB/R e WT/DS401/AB/R. 22 de maio de 2014.

TIMBERLAND CLIMATE STRATEGY. 2009. Disponível em: <http://community.timberland.com/Resource_/PageResource/Corporate-Responsibility/ Reporting-Downloads/Timberlands-Climate-Strategy_2009-Report.pdf $>$. Acesso em: 10 jul. 2015.

\title{
Resumo
}

\section{Padrões Privados e a Atuação ou Omissão do Estado: Protecionismo Público-Privado?}

\begin{abstract}
A crescente proliferação de padrões privados no comércio internacional tem gerado preocupação quanto à possibilidade de representarem novo tipo de protecionismo às margens das regras da OMC. As regras multilaterais de comércio são aplicáveis à conduta de seus membros e não abrangem, portanto, esse tipo de protecionismo privado - caracterizado pela conduta e exigências técnicas, sanitárias e fitossanitárias por parte de entidades privadas, como associação de varejistas, entre outros entes não governamentais. A não aplicação das regras da OMC a entidades privadas pode contribuir para a proliferação desse tipo de regulação privada, uma vez que governos podem criar estímulos à atuação de entes não governamentais como forma de se esquivar das regras multilaterais de comércio. Nesse contexto, em que medida esses esquemas de certificação privada contam com envolvimento governamental para os efeitos da aplicação das regras da OMC? Com base na análise de três estudos de caso, verificou-se que, em diversas situações, é possível identificar diferentes níveis de envolvimento governamental em esquemas regulatórios privados. Em alguns casos, é possível, dessa forma, atribuir responsabilidade ao Estado pela conduta de entes privados em seu território. Em outros, contudo, torna-se necessário o esclarecimento de alguns termos constantes no Acordo sobre Barreiras Técnicas da OMC.
\end{abstract}

Palavras-chave: Padrão Privado - OMC - Responsabilidade do Estado Protecionismo - Acordo TBT 
Abstract

\section{Private Standards and the Action or Omission of the State? Public-Private Protectionism?}

The proliferation of private standards in international trade raises concerns regarding the possibility of these measures be creating a new type of protectionism at the fringes of the WTO. WTO rules apply to actions undertaken by its Members and therefore they do not cover this type of private protectionism, which is characterized by trade restrictive measures adopted by private entities, such as an association of retailers, among other non-governmental entities. The non-application of WTO rules to private entities can contribute to private regulation, since governments may create incentives for the regulation by non-governmental entities so as to circumvent multilateral trade rules. In this context, to what extent are governments involved in private certification schemes so that WTO law could legitimately apply? Based on the analysis of three case studies, it was found that, in many situations, governments may be involved in private regulation in different levels. Therefore, in some cases, it is possible to attribute responsibility to the State for the conduct of private entities in its territory. However, in other situations, the clarification of some terms in the TBT Agreement remains as an important issue for a final decision regarding the application of WTO law to private standards.

Keywords: Private Standards - WTO - State Responsibility Protectionism - TBT Agreement 